\title{
Effectiveness of balance training with kinesthetic ability trainer (KAT 2000) in patients with peripheral neuropathic pain: a randomised controlled study
}

\author{
Duygu Kerim $\odot$, Aslıhan Uzunkulaoğlu๑, Saime Ay॰ \\ Department of Physical Medicine and Rehabilitation, Ufuk University School of Medicine, Ankara, Turkey
}

DOI: $10.18621 /$ eurj.408381

\begin{abstract}
Objectives: The aim of this study isto determine the effectiveness of balance training with Kinesthetic Ability Trainer (KAT 2000) in patients with peripheral neuropathic pain related balance disorder.

Methods: Sixty patients were included into this controlled prospective study and randomized into either balance exercises group (Group 1) or KAT 2000 exercises group (Group 2). Balance exercises were given to all patients.Also, KAT 2000 balance exercises were given all patients in Group $2(n=30)$. All patients received 45-min individualized training session for three times a week for 4 weeks. Douleur Neuropathique 4 (DN4) questionnaire for neuropathic pain; visual analogue scale (VAS) for pain severity; KAT 2000 for static and dynamic balance; Nottingham Health Profile (NHP) for Quality of Life (QoL) was used. Dynamic balance and mobility also was assessed using the Berg Balance Scale (BBS) and Time Up and Go (TUG) test. Patients were evaluated at baseline and the end of the 4-week exercise program.

Results: At the end of the treatment; VAS, BBS, KAT 2000, TUG, NHP, physical activity, NHP pain, NHP social isolation and NHP emotional reactions scores improved significantly in both groups $(p<0.05)$ except NHP sleep and NHP energy level scores in balance exercises group $(p>0.05)$. Statistical differences in VAS pain on movement, global assessment of patient, global assessment of doctor, NHP energy level scores were found between the groups $(p<0.05)$; but there were no statistical difference in VAS at rest, VAS at night, BBS, KAT 2000, TUG, NHP physical activity, NHP pain, NHP sleep, NHP social isolation and NHP emotional reactions scores between the groups $(p>0.05)$.

Conclusion: When combined with the KAT 2000 device, positive effects of balance-coordination exercises on pain on movement and energy level are more evident in patients with peripheral neuropathic pain.
\end{abstract}

Keywords: Neuropathic pain, balance, KAT 2000, quality of life

Received: March 21, 2018; Accepted: July 14, 2018; Published Online: November 23, 2018

N europathic pain is a chronic pain disorder caused by a lesion or disease of the somatosensory system [1]. Neuropathic pain syndromes can be divided into two general categories as consequences of a peripheral or central lesion or peripheral or central dis- ease [2]. Neuropathic pain affects millions of people all over the world. Patients experience one of many symptoms, such as pain, paresthesia, dysesthesia, hyperalgesia, and allodynia [3].

Balance disorders are more common as people get

Address for correspondence: Aslihan Uzunkulaoğlu, MD., Assistant Professor, Ufuk University School of Medicine, Department of Physical Medicine and Rehabilitation, Dr. Ridvan Ege Hastanesi, 06520 Balgat, Ankara, Turkey

E-mail: aslihanseyrek@gmail.com,Tel: +90 312 2044358,Fax:+90 3122872390 
older. It can reduce mobility and independence in the elderly and can cause substantial morbidity and mortality $[4,5]$. The fact that an increased incidence of nerve conduction abnormalities has been found in elderly with a history of balance impairment also suggests that peripheral nerve dysfunction can contribute to balance impairments [6]. It is known that distal sensory peripheral neuropathy and motor impairments may cause postural instability in elderly [7]. The association between peripheral neuropathy and balance impairments has been noted by many authors. It is known that subjects with peripheral neuropathy balanced less reliably on one foot for three seconds than did matched control subjects without peripheral neuropathy [8].

In treatment, various exercise programs should be given to treat the balance impairments identified in the elderly people with peripheral neuropathy. Kinesthetic Ability Trainer (KAT 2000) is a device which consists of two components including a movable platform and a tilt sensor connected to a computer and evaluates and improves the balance ability. In static balance exercises with KAT 2000; patients try to keep the red X symbol located in the center of the computer screen, while in dynamic balance exercises they try to follow the red X symbol moving clockwise or counterclockwise. In this study, we aimed to evaluate the effectiveness of KAT 2000 in the treatment of patients with peripheral neuropathic pain related balance disorder.

\section{METHODS}

\section{Experimental Approach to the Problem}

This placebo randomized controlled trial was carried out in a university hospital and was conducted in accordance with the Declaration of Helsinki. The study protocol was approved by the university ethics committee with 30112015-4 registry number. A total of 60 patients who developed peripheral neuropathic pain-related balance impairment were included into this study and randomized into either balance exercises groups or KAT 2000 exercises groups. All participants were informed about the study and signed written informed consent forms before interventions. Outcome variables were selected to provide scores and before and after treatment these scores were compared.

\section{Subjects}

A total of 60 patients who developed peripheral neuropathic pain-related balance impairment in the chronic phase due to lumber disc herniation, lumber spondylosis and gonarthrosis were included in the study. Patients had neuropathic pain for more than 3 months. Neuropathic pain was diagnosed if Douleur Neuropathique 4 (DN4) score was $\geq 4$. Balance assessment was done with the Berg Balance Scale. Individuals were included in the study who had DN4 scores $\geq 4$ and moderately impaired balance with a score of 21-40 points on the Berg Balance Scale. Individuals were excluded in the study who had history of previous cerebrovascular events; other neurological, musculoskeletal, inner ear or eye disease that may lead to impaired vision or standing balance. Because it may affect balance tests; lower extremity surgery history, knee infection, inflammatory diseases like rheumatoid arthritis and spondyloarthropathies, another cause of polyneuropathy like diabetes mellitus, vitamin B 12 deficiency, toxic or neurological disease like stroke, spinal cord injury, sedative drug use story, heart failure not under active control, malignancy or active systemic disease.

Detailed anamnesis of all patients were obtained. Number of falls, associated systemic diseases and medications were recorded. All patients were examinedin detail with musculoskeletal and neurological examination. After physical examination all patients were received complete blood count, Creactive protein (CRP), erythrocyte sedimentation rate (ESR) and biochemical markers were evaluated. Patients whose test results were within the normal range were included in the study.

By using the website randomizer.org method participants were randomly assigned into two either balance exercises $(n=30)$ or KAT 2000 balance exercise $(n=30)$ group [9]. All of the patients were blinded to training allocation but the physiotherapist who applied thebalance training program was aware of the procedure. Also physiatrist who made the examination and evaluations were blinded to training allocation.

\section{Outcome Measures}

Patients were evaluated at baseline and 4 weeks later. The outcome measures used in the study are listed below. 


\section{Neuropathic Pain}

Neuropathic pain was determined by the Douleur Neuropathique 4 (DN4) questionnaire. The DN4 questionnaire was originally developed for neuropathic pain diagnosis [10]. DN4 consists seven items related to symptoms and three related to clinical examination. For each item, a score of " 1 " is given if the response is "yes" and a score of " 0 " is given if it is "no". The patient is considered to have neuropathic pain if the total score is calculated to be 4 or more. The reliability and validity study of Turkish version of DN4 was performed by Cevik et al. [11].

\section{Pain Intensity}

Pain intensity was evaluated on visual analog scale (VAS), where $0=$ no pain and $10=$ worst possible pain (12). VAS consists of three mean scores; at rest, on movement and pain at night scores. All patients completed this scale.

\section{Quality of Life}

The quality of life was assessed using Nottingham Health Profile (NHP). All patients completed the NHP. This contains 38 statements (answered 'yes' or 'no') that assess subjective distress in six sections: physical activity (eight items), pain (eight items), sleep (five items), emotional reactions (nine items), social isolation (five items) and energy level (three items) [13].

O'Brien's method was used in NHP score calculation. In order to calculate the overall score; the item weights for items answered affirmatively are added, and this total score is divided by 600 (the sum of all item weights); the result is subtracted from 1.In order to calculate the score for each section, total weight score of each section is divided by 100 , the result is subtracted from $1[14,15]$. According to these methods, when the evaluation score is close to 'zero', it shows poor health status and when it is close to 'one', it shows good health status. The methods described above were used in NHP score calculation in this study.

\section{Static and Dynamic Balance \\ Kinesthetic Ability Trainer 2000 (KAT 2000)}

The KAT2000 device consists of two components including a movable platform and a tilt sensor connected to a computer. In static balance measurement, patients were instructed to cross their arms against their chest and maintain body equilibrium without changing feet on the platform. During the test, patients were asked to keep the red X symbol located in the middle of the computer screen.In dynamic balance measurement, patients were instructed to follow the red $\mathrm{X}$ symbol located in the center of the computer screen. During the test, circling in the clockwise direction, counterclockwise rotation in the clockwise direction, square drawing, eight strokes were performed. All patients performed each test for $30 \mathrm{~s}$ and repeated three times. The best of the three scores was considered as the final score. In calculating test scores, low scores indicate that the balance index is good. The reliability of the balance data with the use of the KAT has been explained previously [16].

\section{Berg Balance Scale}

Dynamic balance and mobilitywas also evaluated using the Berg Balance Scale (BBS) and Time Up and Go (TUG) test. The BBS consists of 14 simple different balance-related tasks and evaluates the ability of the subject's static, dynamic, and functional balance. The success of each task was evaluated using a scoring scale between zero (unable) and four (independent). Total scores was calculated out of a maximum of 56 points (17). The validity and reliability of the Turkish version of the BBS was studied byŞahin et al (18).

\section{Time Up and Go (TUG)}

The TUG test is a simple test used to evaluate mobility [19]. Patients were instructed to rise from a chair, walk $3 \mathrm{~m}$ on the floor at a normal pace, turn around, walk back to the chair, and sit down [20]. The researcher observed the patient's postural stability, gait and stride length while the participants were walking. One source proposes that scores of 10 seconds (sec) or less indicate normal mobility, 11-20 sec normal limits for frail elderly subjects, and scores of $30 \mathrm{sec}$ or more propose that the subjects may fall [21, 22].

\section{Procedures}

Before balance training, warm-up and stretching exercises (paraspinal stretching, gluteus maximus and hip flexors stretching, hamstring stretching, 
gastroknemius and soleus stretching $1 \times 10$ repetition) were given all patients for 10 minutes.

In group 1, balance exercises contained postures designed to gradually reduce the base of support (2legged stand, semi-tandem stand, tandem stand, 1-legged stand), dynamic movements to disturb the center of gravity (tandem walk, circle turns), exercises to stress the postural muscle groups (heel or toe stands) and exercises to reduce sensory input (standing with eyes closed) as recommended by the American College of Sports Medicine [22]. Subjects received 45-min individualized training session for three times a week for 4 weeks.

In group 2, balance exercises were given all patients. At the same time, balance exercises were given with Kinesthetic Ability Trainer 2000 (KAT 2000). In static balance exercises with KAT 2000; patients were asked to cross their arms against their chest and maintain body equilibrium without changing feet on the platform. During this time, patients were instructed to keep the red X symbol located in the center of the computer screen. In dynamic balance exercises with KAT2000; patients were instructed to follow the red X symbol located in the center of the computer screen. During this time, circling in the clockwise direction, counterclockwise rotation in the clockwise direction, square drawing, eight strokes are performed. Each test was performed for $30 \mathrm{sec}$ and repeated three times. Increased measurements indicate a poor balance performance. The best of the three scores was accepted as the final score.Patients received 45-min individualized training session for three times a week for 4 weeks.

At the end of the balance training, cool-down exercises were given for 10 minutes, three times a week for 4 weeks in both groups.

\section{Statistical Analysis}

The means and standard deviations were given as descriptive statistics. Wilcoxon test was used to calculate the pre and post-treatment value differences. To compare the differences between two groups, Mann Whitney U was used. A level of significance of $p<0.05$ was accepted. All analyses were performed using the SPSS for Windows 20.0 software program.

Table 1. Demographic characteristics and baseline values of the outcome measures

\begin{tabular}{lccc}
\hline Variables & $\begin{array}{c}\text { Group 1 } \\
(\mathbf{n}=\mathbf{3 0})\end{array}$ & $\begin{array}{c}\text { Group 2 } \\
(\mathbf{n}=\mathbf{3 0})\end{array}$ & $\boldsymbol{p}$ value \\
\hline Age & $75.70 \pm 6.71$ & $75.43 \pm 6.54$ & 0,85 \\
Sex (Female/Male) & $25 / 5$ & $25 / 5$ & 1.00 \\
DN4 score & $7.66 \pm 0.71$ & $7.93 \pm 0.63$ & 0.14 \\
VAS at rest & $4.73 \pm 0.98$ & $4.23 \pm 1.19$ & 0.50 \\
VAS on movement & $7.00 \pm 0.87$ & $7.26 \pm 0.78$ & 0.25 \\
VAS pain at night & $4.83 \pm 0.79$ & $4.63 \pm 0.66$ & 0.43 \\
Global assessment of patient & $7.53 \pm 0.68$ & $7.53 \pm 0.68$ & 0.84 \\
Global assessment of doctor & $7.43 \pm 0.67$ & $7.40 \pm 0.77$ & 0.96 \\
BBS score & $28.00 \pm 5.31$ & $30,13 \pm 6.18$ & 0.16 \\
KAT 2000 static score & $1690.33 \pm 520.38$ & $1505,30 \pm 556.30$ & 0.18 \\
KAT 2000 dynamic score & $2195.26 \pm 530.20$ & $2057.30 \pm 565.88$ & 0.26 \\
TUG & $11.36 \pm 2.42$ & $10.9 \pm 2.41$ & 0.45 \\
NHP physical activity & $0.46 \pm 0.20$ & $0.51 \pm 0.20$ & 0.32 \\
NHP pain & $0.25 \pm 0.24$ & $0.25 \pm 0.22$ & 0.82 \\
NHP sleep & $0.56 \pm 0.39$ & $0.70 \pm 0.41$ & 0.28 \\
NHP social isolation & $0.71 \pm 0.33$ & $0.77 \pm 0.29$ & 0.46 \\
NHP emotional reactions & $0.69 \pm 0.18$ & $0.66 \pm 0.19$ & 0.40 \\
NHP energy level & $0.39 \pm 0.39$ & $0.23 \pm 0.41$ & 0.10 \\
\hline
\end{tabular}

Data are shown as mean \pm standard deviation. DN4 $=$ Douleur Neuropathique $4, \mathrm{VAS}=$ visual analog scale, BBS $=$ Berg Balance Scale, KAT $2000=$ Kinesthetic Ability Trainer 2000, TUG $=$ Time Up and Go, NHP = Nottingham Health Profile 


\section{RESULTS}

A total of 60 subjects completed the 4-week exercise program. The demographic characteristics and baseline values of the outcome measures of the patients are presented in Table 1. There were no statistically significant differences between the groups for baseline values $(p>0.05)$ (Table 1).

At the end of the 4-week treatment periods; VAS at rest ( $p<0.01$ for both groups), VAS pain on movement ( $p<0.01$ for both groups), VAS pain at night ( $p=0.01$ for Group 1, $p<0.01$ for Group 2),
BBS ( $p<0.01$ for both groups), KAT 2000 static ( $p<$ 0.01 for both groups), KAT 2000 dynamic $(p<0.01$ for both groups), TUG test ( $p<0.01$ for both groups), NHP physical activity ( $p<0.01$ for both groups), NHP pain ( $p<0.01$ for both groups), NHP social isolation ( $p=0.01$ for Group 1, $p<0.01$ for Group 2) and NHP emotional reactions ( $p<0.01$ for both groups) scores improved significantly in both groups $(p<0.05)$. At the end of the therapy there were no statistically significant difference forNHP sleep $(p=0.10)$ and NHP energy level ( $p=0.10)$ scoresin Group 1; but there were statistically significant difference for these

Table 2. Comparison of the outcome measures in both groups before and after treatment.

\begin{tabular}{|c|c|c|c|c|}
\hline Variables & & $\begin{array}{l}\text { Group } 1 \\
(n=30)\end{array}$ & $\begin{array}{l}\text { Group } 2 \\
(n=30)\end{array}$ & $p$ value \\
\hline \multicolumn{5}{|l|}{ VAS at rest } \\
\hline Before treatment & & $4.73 \pm 0.98$ & $4.23 \pm 1.19$ & 0.75 \\
\hline \multirow{2}{*}{ After treatment } & & $3.83 \pm 0.94$ & $4.00 \pm 1.14$ & \\
\hline & $p$ value & $<0.01$ & $<0.01$ & \\
\hline \multicolumn{5}{|c|}{ VAS pain on movement } \\
\hline Before treatment & & $7.00 \pm 0.87$ & $7.26 \pm 0.78$ & $<0.01$ \\
\hline \multirow[t]{2}{*}{ After treatment } & & $5.53 \pm 1.13$ & $6.66 \pm 0.95$ & \\
\hline & p value & $<0.01$ & $<0.01$ & \\
\hline \multicolumn{5}{|l|}{ VAS pain at night } \\
\hline Before treatment & & $4.83 \pm 0.79$ & $4.63 \pm 0.66$ & 0.10 \\
\hline \multirow[t]{2}{*}{ After treatment } & & $3.93 \pm 0.78$ & $4.23 \pm 0.50$ & \\
\hline & $p$ value & 0.01 & $<0.01$ & \\
\hline \multicolumn{5}{|c|}{ Global assessment of patient } \\
\hline Before treatment & & $7.53 \pm 0.68$ & $7.53 \pm 0.68$ & $<0.00$ \\
\hline \multirow[t]{2}{*}{ After treatment } & & $5.36 \pm 0.66$ & $6.73 \pm 0.73$ & \\
\hline & $p$ value & $<0.01$ & $<0.01$ & \\
\hline \multicolumn{5}{|c|}{ Global assessment of doctor } \\
\hline Before treatment & & $7.43 \pm 0.67$ & $7.40 \pm 0.77$ & $<0.01$ \\
\hline \multirow[t]{2}{*}{ After treatment } & & $5.20 \pm 0.71$ & $6.56 \pm 0.81$ & \\
\hline & $p$ value & $<0.01$ & $<0.01$ & \\
\hline \multicolumn{5}{|l|}{ BBS score } \\
\hline Before treatment & & $28.00 \pm 5.31$ & $30.13 \pm 6.18$ & 0.47 \\
\hline \multirow[t]{2}{*}{ After treatment } & & $35.03 \pm 5.67$ & $34.00 \pm 6.25$ & \\
\hline & $p$ value & $<0.01$ & $<0.01$ & \\
\hline \multicolumn{5}{|c|}{ KAT 2000 static score } \\
\hline Before treatment & & $1690.33 \pm 520.38$ & $1505.30 \pm 556.30$ & 0.63 \\
\hline \multirow[t]{2}{*}{ After treatment } & & $1280.10 \pm 532.99$ & $1202.76 \pm 555.55$ & \\
\hline & $p$ value & $<0.01$ & $<0.01$ & \\
\hline \multicolumn{5}{|c|}{ KAT 2000 dynamic score } \\
\hline Before treatment & & $2195.26 \pm 530.20$ & $2057.30 \pm 565.88$ & 0.40 \\
\hline \multirow[t]{2}{*}{ After treatment } & & $1585.60 \pm 536.86$ & $1722.70 \pm 562.84$ & \\
\hline & $p$ value & $<0.01$ & $<0.01$ & \\
\hline
\end{tabular}


Table 2 Continued.

\begin{tabular}{|c|c|c|c|c|}
\hline Variables & & $\begin{array}{l}\text { Group } 1 \\
(n=30)\end{array}$ & $\begin{array}{c}\text { Group } 2 \\
(n=30)\end{array}$ & $p$ value \\
\hline \multicolumn{5}{|l|}{ TUG } \\
\hline Before treatment & & $11.36 \pm 2.42$ & $10.9 \pm 2.41$ & 0.05 \\
\hline \multirow[t]{2}{*}{ After treatment } & & $7.66 \pm 2.20$ & $8.90 \pm 2.39$ & \\
\hline & $p$ value & $<0.01$ & $<0.01$ & \\
\hline \multicolumn{5}{|c|}{ NHPphysical activity } \\
\hline Before treatment & & $0.46 \pm 0.20$ & $0.51 \pm 0.20$ & 0.55 \\
\hline \multirow[t]{2}{*}{ After treatment } & & $0.70 \pm 0.15$ & $0.72 \pm 0.16$ & \\
\hline & $p$ value & $<0.01$ & $<0.01$ & \\
\hline \multicolumn{5}{|l|}{ NHP pain } \\
\hline Before treatment & & $0.25 \pm 0.24$ & $0.25 \pm 0.22$ & 0.21 \\
\hline \multirow[t]{2}{*}{ After treatment } & & $0.55 \pm 0.14$ & $0.48 \pm 0.18$ & \\
\hline & $p$ value & $<0.01$ & $<0.01$ & \\
\hline \multicolumn{5}{|l|}{ NHP sleep } \\
\hline Before treatment & & $0.56 \pm 0.39$ & $0.70 \pm 0.41$ & 0.38 \\
\hline \multirow[t]{2}{*}{ After treatment } & & $0.69 \pm 0.31$ & $0.74 \pm 0.38$ & \\
\hline & $p$ value & 0.10 & $<0.01$ & \\
\hline \multicolumn{5}{|c|}{ NHP social isolation } \\
\hline Before treatment & & $0.71 \pm 0.33$ & $0.77 \pm 0.29$ & 0.52 \\
\hline \multirow[t]{2}{*}{ After treatment } & & $0.87 \pm 0.19$ & $0.89 \pm 0.18$ & \\
\hline & $p$ value & 0.01 & $<0.01$ & \\
\hline \multicolumn{5}{|c|}{ NHP emotional reactions } \\
\hline Before treatment & & $0.69 \pm 0.18$ & $0.66 \pm 0.19$ & 0.37 \\
\hline \multirow[t]{2}{*}{ After treatment } & & $0.91 \pm 0.10$ & $0.88 \pm 0.11$ & \\
\hline & $p$ value & $<0.01$ & $<0.01$ & \\
\hline \multicolumn{5}{|l|}{ NHP energy level } \\
\hline Before treatment & & $0.39 \pm 0.39$ & $0.23 \pm 0.41$ & 0.01 \\
\hline \multirow[t]{2}{*}{ After treatment } & & $0.67 \pm 0.39$ & $0.28 \pm 0.42$ & \\
\hline & $p$ value & 0.10 & 0.01 & \\
\hline
\end{tabular}

Data are shown as mean \pm standard deviation. DN4 = Douleur Neuropathique 4, VAS = visual analog scale, BBS = Berg Balance Scale, KAT 2000 = Kinesthetic Ability Trainer 2000, TUG = Time Up and Go, NHP = Nottingham Health Profile

scores in Group 2 ( $p<0.01$ for both scores) (Table 2).

After the treatment, statistical differences in VAS pain on movement $(p<0.01)$, global assessment of patient $(p<0.01)$, global assessment of doctor $(p<$ $0.01)$, NHP energy level $(p=0.01)$ scores were found between the groups $(p<0.05)$ (Table 2). There were no statistical difference in VAS at rest $(\mathrm{p}=0.75)$, VAS at night $(p=0.10)$, BBS $(p=0.47)$, KAT 2000 static $(p=0.63)$, KAT 2000 dynamic $(p=0.40)$ TUG test $(p$ $=0.05)$, NHP physical activity $(p=0.55)$, NHP pain $(p=0.21)$, NHP sleep $(p=0.38)$, NHP social isolation $(p=0.52)$ and NHP emotional reactions $(p=0.37)$ scores between the groups at the end of the treatment $(p>0.05)$ (Table 2).

\section{DISCUSSION}

Balance is important for daily activities, with increasing age the balance function of older people will decline because of age-related physiological changes, such as decreased muscle strength, increased passive tissue stiffness and decreased nerve conduction velocity [23-25]. The fact that an increased incidence of nerve conduction abnormalities has been found in elderly with a history of balance impairment also suggests that peripheral nerve dysfunction can contribute to balance impairments [7]. Thus, balance exercises are important to maintain and improve balance function in older adults with peripheral 
neuropathic pain.

In peripheral neuropathy, patients experience balance impairment during stance and gait because of the sensory proprioception system of the lower extremity that plays a key role in balance control is affected and also the afferent conduction of tactile and proprioceptive information is impaired [26-28].

Balance exercises are important to maintain and improve balance function in older adults with peripheral neuropathic pain. Allet et al. [29] reported that strength and balance training significantly improved balance and strength, increased walking speed, and decreased fear of falling in patients with peripheral neuropathy.

In this study, we included the patients with peripheral neuropathic pain-related balance impairment in the chronic phase due to lumber disc herniation, lumber spondylosis and gonarthrosis. Frost et al. mentioned that radiculopathy may affect balance control the result of delaying muscle activation timing in patients with low back pain [30]. In the present study,we found that balance exercises and KAT 2000 exercises significantly improved VAS, KAT 2000, BBS, TUG, NHP physical activity, NHP pain, NHP social isolation and NHP emotional reactions scores. In that study, static balance test was performed with the person standing on the dominant leg and the dynamic balance test was performed with the person standing on both feet. It was mentioned that there was a learning effect on balance when the patients were retested, especially in the dynamic test and the greatest differences was seen in the static test. This was explained that standing on one leg was a daily living activity, while the skills required in the dynamic balance test were new because patient must convert a visual task into a set of coordinated movements [16]. On the other hand, there are many different systems that have been used in improvement of balance except KAT 2000. Nardone et al. [31] reported that balance training with either specific physical exercises or a powered platform is effective in patients with balance disorders of neuropathic origin; thus, they contribute to improving balance and potentially decreasing the risk of falling in patients with neuropathy. In another study, Lindemann et al. [32] compared the effectiveness Biodex stability system (BSS) balance training with a home-based exercise program in nondisabled elderly subjects. At the end of the study, it was shown that computer-assisted balance training, even if focused on one motor skill, was more effective than a home-based exercise program [32].

KAT 2000can also be used as a tool for static and dynamic balance exercises [34]. There are only a few study using the KAT 2000 in balance impairments and in these studies it is used as only a testing device [3335]. As far as we know there is no other study that KAT 2000 has been used as a tool for static and dynamic balance exercises. Therefore we used KAT 2000 as an exercise program to improve static and dynamic balance in patients with peripheral neuropathic pain.In our study, both balance and KAT 2000 exercises significantly improved KAT 2000 static and dynamic scores. On the other hand, KAT 2000 exercise group did not score better than balance exercise group with KAT 2000. So we can conclude that there is no learning effect.Additionally, there were no statistical difference between the groupsat the end of the 4-week.As a result, we can conclude that the combined use of balance and KAT 2000 exercises does not improve neither static nor dynamic balance further.

The BBS and TUG tests are most commonly used to predictdynamic and functional balance in the elderly. In the study of Kruse et al. [36], efficacy of a home-based exercise program in patients with diabetic neuropathy was evaluated and the balance measurements which included the BBS, TUG and one-leg static stance (OLS) tests were collected at the baseline assessment and after 6 and 12 months of participation. No significant differences were noted between groups in neither BBS nor TUG; only OLS test was better in leg strengthening and balance exercises group than motivational telephone calls group. The training program had a minimal effect on participants' static balance [36]. In another study; Song et al. [37] assessed the effects of the balance exercise program on balance and trunk proprioception in the older adults with neuropathies. The BBS and TUG scores which assessed the dynamic balance, significantly increased in the exercise group but did not improve in the controlgruop which did not take exercise program. In that study, balance exercises have shown a positive effect by improving balance and trunk proprioception in older people with neuropathy [37]. In our study, after a 4-week balance training program, patients increased their BBS scores by 7.0 
points in balance exercises groupand 3.8 points inKAT 2000 exercises group. The minimum detectable change of the BBS has been reported to be 7 points for older adults with an initial score of 25-34 [38]. Significant improvement in BBS scores was observed in both groups. All patients decreased their TUG time scores below $13.5 \mathrm{sec}$, a suggested cutoff point for fall risk in the elderly [39]. On the other hand, there were no statistical difference in BBS and TUG time scores between the groups at the end of the 4-week. This situation suggests that the combined use of balanceand KAT 2000 exercises does not improve the dynamic balance further as mentioned before.

Recently, a series of high-quality studies have been published that examine the relationship between neuropathic pain and health-related quality of life. The descriptive studies show that neuropathic pain is reported by patients to have a significant negative impact on sleep, physical functioning, emotional functioning and social functioning [40, 41]. Patients describe pain-related interference in multiple healthrelated quality of lifeand functional domains, as well as reduced ability to work and reduced mobility due to pain [42]. Disturbed sleep is always among the most common pain-related problems reported by individuals with neuropathic pain [41]. Benbow et al. [43] conducted a study on 79 diabetic and 39 nondiabetic patients were assessed using the Nottingham Health Profile (NHP) for the quality of life. Diabetic neuropathy patients had significantly higher scores in 5/6 NHP subgroups than either the other diabetic patients or the non-diabetic control patients. These subgroups were emotional reaction, energy, pain, physical mobility and sleep [43]. In our study, we determined significant improvements at quality of life in both groups except NHP sleep and NHP energy level scores in balance exercise group but this improvement was more significant in KAT 2000 exercise group. There were statistically significant differences in only NHP energy level between the groups. So we can conclude that combined use of balance and KAT 2000 exercises are effective for improvement of sleep and energy level in patients with peripheral neuropathic pain.

There are very few studies on the effect of balance exercise on neuropathic pain. Therefore, it is difficult to compare this study with other studies. In the future, we need to develop different kinds of balance exercises that will improve balance disorder in patients with peripheral neuropathic pain. So research studies should be done continuously to improve the balance and quality of life in patients with peripheral neuropathic pain.

\section{Limitations}

Short duration of exercise programs and followup were the major limitations of the study. In this study, we analyzed only the short-term effects of balance exercise programs, therefore further studies examining the long-term effects should be considered.

\section{CONCLUSION}

The results of our study confirm that 4-week balance and KAT 2000 balance exercise programs are effective in improving pain, static and dynamic balance and quality of life in adults with peripheral neuropathic pain. When combined with the KAT 2000 device, positive effects of balance-coordination exercises on global assessment of patient and doctor, pain on movement and energy level are more evident in patients with peripheral neuropathic pain. So, in an controlled setting; this combined exercise programme improves this burden complication.

\section{Ethical approval}

The project was approved by university Ethical Committee. All procedures were performed in accordance with the ethical standards of the institutional research committee and with the 1964 Helsinki Declaration and its latter amendments.

\section{Informed consent}

Informed consent was obtained from individual participants included in the study.

\section{Conflict of interest}

The authors disclosed no conflict of interest during the preparation or publication of this manuscript.

\section{Financing}

The authors disclosed that they did not receive any grant during conduction or writing of this study. 


\section{REFERENCES}

[1] Jensen TS, Baron R, Haanpää M, Kalso E, Loeser JD, Rice AS, et al. A new definition of neuropathic pain. Pain 2011;152:2204-5.

[2] Meacham K, Shepherd A, Mohapatra DP, Haroutounian S. Neuropathic pain: central vs. peripheral mechanisms. Curr Pain Headache Rep 2017;21:28.

[3] Backonja MM, Serra J. Pharmacologic management part 1: Better studied neuropathic pain diseasese. Pain Med 2004;5:52847.

[4] Gryfe CI, Amies A, Ashley MJ. A longitudinal study of falls in an elderly population: I. Incidence and morbidity. Age Ageing 1977;6:201-10.

[5] Tinetti ME, Speechley M, Ginter SF. Risk factors for falls among elderly persons living in the community. N Engl J Med 1988;319:1701-7.

[6] Pack DR, Wolfson LI, Amerman P, Whipple R, Kaplan JG. Peripheral nerve abnormalities and falling in the elderly. Neurology 1985;35 Suppl 1:79.

[7] Van de Bosh C, Gilsing MG, Lee SG, Richardson JK, Ashton Miller JA. Peripheral neuropathy effect on ankle inversion and eversion thresholds. Arch Phys Med Rehabil 1995;76:850-6.

[8] Richardson JK, Ashton-Miller JA, Lee SG, Jacobs K. Moderate peripheral neuropathy impairs weight transfer and unipedal balance in the elderly. Arch Phys Med Rehabil 1996;77:1152-6.

[9] www.randomizer.org

[10] Bouhassira D, Attal N, Alchaar H, Boureau F, Brochet B, Bruxelle J, et al. Comparison of pain syndromes associated with nervous or somatic lesions and development of a new neuropathic pain diagnostic questionnaire (DN4). Pain 2005;114:29-36.

[11] Unal Cevik I, Sarioglu Ay S, Evcik D. A comparison of the DN4 and LANSS questionnaires in the assessment of neuropathic pain: validity and reliability of the Turkish version of DN4. J Pain 2010;11:1129-35.

[12] Breivik H, Borchgrevink PC, Allen SM, Rosseland LA, Romundstad L. Assessment of

pain. Br J Anaesth 2008;101:17-24.

[13] Hunt SM, McEwen J. The development of a subjective health indicator. Sociol Health Illn 1980;2:231-46.

[14] McDowell I. Measuring health: a guide to rating scales and questionnaires. 3rd ed. Oxford University Press. 2006:pp. 780.

[15] O'Brien BJ, Buxton MJ, Ferguson BA. Measuring the effectiveness of heart transplant programmes: quality of life data and their relationship to survival analysis. J Chronic Dis 1987;40:S137-53.

[16] Hansen MS, Dieckmann B, Jensen K, Jakobsen BW. The reliability of balance tests performed on the kinesthetic ability trainer (KAT 2000). Knee Surg Sports Traumatol Arthrosc 2000;8:180-5.

[17] Berg KO, Wood-Dauphinee SL, Williams JI, Maki B. Measuring balance in the elderly: validation of an instrument. Can J Public Health 1992;83(Suppl 2):S7-S11.

[18] Sahin F, Yilmaz F, Ozmaden A, Kotevolu N, Sahin T, Kuran B. Reliability and validity of the Turkish version of the Berg Balance Scale. J Geriatr Phys Ther 2008;31:32-7.
[19] Podsiadlo D, Richardson S. The timed "Up \& Go": a test of basic functional mobility for frail elderly persons. J Am Geriatr Soc 1991;39:142-8.

[20] Shumway-Cook A, Brauer S, Woollacott M. Predicting the probability for falls in community-dwelling older adults using the Timed Up \& Go Test. Phys Ther 2000;80:896-903.

[21] Bohannon RW. Reference values for the timed up and go test: a descriptive meta-analysis. J Geriatr Phys Ther 2006;29:648 .

[22] American College of Sports Medicine, Chodzko-Zajko WJ, Proctor DN, Fiatarone Singh MA, Minson CT, Nigg CR, Salem GJ, et al. American College of Sports Medicine position stand. Exercise and physical activity for older adults. Med Sci Sports Exerc 2009;41:1510-30.

[23] Valerio BC, Nobrega JA, Tilbery CP. Neural conduction in hand nerves and the physiological factor of age. Arq Neuropsiquiatr 2004;2:114-8.

[24] Perry MC, Carville SF, Smith IC, Rutherford OM, Newham DJ. Strength, power output and symmetry of leg muscles: effect of age and history of falling. Eur J Appl Physiol 2007;100:55361.

[25] DeVita P, Hortobagyi T. Age increases the skeletal versus muscular component of lower extremity stiffness during stepping down. J Gerontol Ser A Biol Sci Med Sci 2000;55:B593-600.

[26] Nardone A, Godi M, Artuso A, Schieppati M. Balance rehabilitation by moving platform and exercises in patients with neuropathy or vestibular deficit. Arch Phys Med Rehabil 2010;91:1869-77.

[27] Horlings CG, Kung UM, Bloem BR, Honegger F, Van Alfen $\mathrm{N}$, Van Engelen BG, et al. Identifying deficits in balance control following vestibular or proprioceptive loss using posturographic analysis of stance tasks. Clin Neurophysiol 2008;119:2338-46.

[28] Van Deursen RW, Simoneau GG. Foot and ankle sensory neuropathy, proprioceptionand postural stability. J Orthop Sports Phys Ther 1999;29:718-26.

[29] Allet L, Armand S, de Bie RA, Golay A, Monnin D, Aminian $\mathrm{K}$, de Bruin ED. The gaitand balance of patients with diabetes can be improved: a randomised controlled trial. Diabetologia 2010;53:458-66.

[30] Frost, Lydia R., Brown, Stephen H.M. Muscle activation timing and balance response inchronic lower back pain patients with associated radiculopathy. Clinical Biomechanics 2016;32:124-30.

[31] Nardone A, Godi M, Artuso A, Schieppati M. Balance rehabilitation by moving platformand exercises in patients with neuropathy or vestibular deficit. Arch Phys Med Rehabil 2010;91:1869-77.

[32] Lindemann U, Rupp K, Muche R, Nikolaus T, Becker C. Improving balance byimproving motor skills. Z Gerontol Geriatr 2004;37:20-6.

[33] France P, Derscheid G, Irrgang J, Malone T, Petersen R, Tippett $\mathrm{S}$ et al. Preliminary clinical evaluation of the Breg K.A.T.: effects of training in normals. Isokinet Exerc Sci 1992;2:133-9. [34] Crawford C, Fleming K, Karabatsos P, Volkmann C, Williams K, Newton R. Normative values for healthy young and 
elderly adult populations on the KAT balance system. Issues Aging 1995;18:10-4.

[35] Johnston RB, Howard ME, Cawley PW, Losse GM. Effect of lower extremity muscular fatigue on motor control performance. Med Sci Sports Exerc 1998;30:1703-7.

[36] Kruse RL, LeMaster JW, Madsen RW. Fall and balance outcomes after an intervention to promote leg strength, balance, and walking in people with diabetic peripheral neuropathy: "Feet First" randomized controlled trial. Phys Ther 2010;90:1568-79. [37] Song CH, Petrofsky JS, Lee SW, Lee KJ, Yim JE. Effects of an exercise program onbalance and trunk proprioception in older adults with diabetic neuropathies. Diabetes Technol Ther 2011;13:803-11.

[38] Donoghue D; Physiotherapy Research and Older People (PROP) group, Stokes EK. Howmuch change is true change? The minimum detectable change of the Berg Balance Scale inelderly people. J Rehabil Med 2009;41:343-6.

[39] Shumway-Cook A, Brauer S, Woollacott M. Predicting the probabilityfor falls incommunity-dwelling older adults using the Timed Up \& Go Test. Phys Ther 2000;80:896-903.

[40] David J. Rowbotham. Neuropathic pain and quality of life. European Journal of Pain 2002;6 (Suppl. B):19-24.

[41] Jensen MP, Chodroff MJ, Dworkin RH. The impact of neuropathic pain on health-relatedquality of life: review and implications. Neurology 2007;68:1178-82.

[42] O'Connor AB. Neuropathic pain: quality-of-life impact, costs and cost effectiveness of therapy. Pharmacoeconomics 2009;27:95-112.

[43] Benbow SJ, Wallymahmed ME, MacFarlane IA. Diabetic peripheral neuropathy and quality of life. OJM 1998;91:733-7. 